\title{
PENGUKURAN KINERJA BPRS BERDASARKAN PERSPEKTIF TAUHIDY STRING RELATION (TSR) (Studi Kasus Pada PT BPRS Muamalat Harkat Bengkulu)
}

\author{
Dharma Setiawan ${ }^{1)}$; Katra Pramadeka ${ }^{2)}$ \\ 1) Department of Islamic Economic Faculty of Economic and Business, \\ Universitas Muhammadiyah Bengkulu \\ Email: ${ }^{1)}$ 12dharmasetiawan@gmail.com ; ${ }^{2)}$ katrapramadeka@gmail.com
}

\section{How to Cite :}

Setiawan, D. (2020). PENGUKURAN KINERJA BPRS BERDASARKAN PERSPEKTIF TAUHIDY STRING RELATION (TSR) (Studi Kasus Pada PT BPRS Muamalat Harkat Bengkulu. EKOMBIS REVIEW: Jurnal IImiah Ekonomi Dan Bisnis, 3(1). DOI: https://doi.org/13.11114/ekombisreview.1.x.x1-x2

\section{ARTICLE HISTORY}

Received [20 05 2020]

Revised [1 07 2020]

Accepted [28 07 2020]

\section{KEYWORDS \\ TSR, Tauhidy String Relation}

This is an open access article under the $C C-B Y-S A$ license

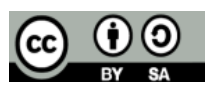

\section{ABSTRAK}

Studi mengenai manajemen atau pengelolaan kinerja suatu institusi/organisasi bisnis, telah banyak dikaji dalam berbagai riset/penelitian Terutama pengukuran kinerja pada sektor industri keuangan mikro dengan berbagai macam derivasi/turunannya yang sesuai dengan prinsip prinsip ajaran agama Islam, masih belum banyak dikaji dan dikembangkan oleh kaum Muslim. Bank Pembiayaan Rakyat Syariah (BPRS) merupakan lembaga keuangan yang bergerak dalam pelayanan keuangan masyarakat, berbasis prinsip syariah. Berdasarkan perspektif TSR, dimana setiap variabel telah mengalami proses knowledge induced- $(\theta)$, dan Wellbeing selalu sebagai dependent variable. Pada prinsipnya penerapan Pengukuran Kinerja BPRS Muamalat Harkat Bengkulu dengan menggunakan perspektif atau pendekatan metodologi Tawhidy String Relation (TSR), dimana ukuran "Moralitas", "Etika" dan "Nilai nilai Sosial" (MEN).Penelitian ini menggunakan data primer dan sekunder melalui studi kepustakaan, interviewed para pelaku, observasi, kuesioner dan data sekunder indikator BPRS, Bengkulu. Secara umum hasil pengukuran nilai $(\theta)$ sangat baik, mendekati nilai 4 dengan skala Likert(5). Nilai terbesar pada variabel aspek komunitas 3,91 dan terendah pada aspek keberlanjutan bisnis 3,83 . Penjelasan yang umum BPRS memang harus dekat dengan komunitas atau warga setempat. Dan kondisi terlemah adalah tentang keberlanjutan bisnis, sebagaimana bisnis ukuran kecil pada umumnya.Nilai $(\theta)$ terkecil juga ditunjukan pada nilai pencapaian rasional yang paling kecil yaitu hanya mencapai 50. Pertumbuhan keuntungan sangat tinggi, mencapai $39 \%$, sedangkan NPF juga sangat tinggi, hal ini mengindikasikan suatu kebijakan yang kurang cocok. Seolah shareholders menginginkan laba yang tinggi, dengan tidak mencadangkan kerugian atas NPF 
yang juga tinggi. Akibatnya secara logis keberlanjutan usaha menjadi dipertaruhkan.

\section{ABSTRACT}

Studies on the management or management of the performance of an institution / business organization, have been widely studied in various studies / research Especially the measurement of performance in the microfinance industry sector with a variety of derivations / derivatives that are in accordance with the principles of the teachings of Islamic religion, still not widely studied and developed by the Muslims. Islamic People's Financing Bank (BPRS) is a financial institution engaged in public financial services, based on sharia principles. Historically, SMK or PMS have long been implemented as part of management science.

In principle, the application of the Performance Measurement of the Muamalat Harkat BPRS Bengkulu using the perspective or methodology approach of Tawhidy String Relations (TSR), which measures "Morality", "Ethics" and "Social Value" (MEN).This research uses primary and secondary data through literature study, interviewed by the actors, observations, questionnaires and secondary data for BPRS indicators, Bengkulu. In general the results of measurement of value $(\theta)$ are very good, approaching value 4 with a Likert scale (5). The highest value is on the community aspect variable 3.91 and the lowest is on the business sustainability aspect 3.83. A common explanation is that the BPRS must be close to the community or local residents. And the weakest condition is about business sustainability, as are small businesses in general.Profit growth is very high, reaching 39\%, while NPF is also very high, this indicates a policy that is not suitable. As if shareholders want high profits, by not reserving losses on NPF which is also high. As a result, logically the sustainability of the business is at stake.

\section{PENDAHULUAN}

Pengukuran kinerja Bank Pembiayaan Rakyat Syariah (BPRS) berdasarkan kaidah atau prinsip prinsip dasar pengukuran Sistem Managemen Kinerja (SMK) atau Performance Management System (PMS) yang sudah banyak diimplementasikan oleh institusi/organisasi bisnis atau korporasi. Pendekatan dan konsep pemikiran dengan sudut pandang metodologi Tawhidy String Relation (TSR), selanjutnya digunakan sebagai instrument evaluasi dengan kandungan moralitas, etika dan nilai nilai sosial sebagai alat ukur utama. Studi mengenai BPRS dan Micro Finance Institutions (MFI) di Indonesia juga telah banyak dilakukan dengan berbagai pendekatan, termasuk dalam penilaian kinerja dan berbagai aspek terkait. Hartungi (2007), dalam studi tentang keberhasilan dari Bank Rakyat Indonesia (BRI) dalam menjalankan bisnis mikro di Makasar, yang terkait dengan kondisi sosio-kultural masyarakat setempat. Dalam kajian Usul Figh, beberapa Hadits Nabi Muhammad SAW yang dapat diinterpretasikan terkait dengan kegiatan bisnis adalah: Bila suatu urusan tidak dikerjakann oleh ahlinya, maka tunggulah kehancurannya. Bekerjalah solah-olah 
anda akan hidup selamanya di dunia, dan berdoalah seolah olah anda akan mati besok. Bila anda mempekerjakan buruh, maka bayarlah sebelum kering keringatnya. Mereka mengharapkan perdagangan yang tidak akan merugi (QS. Fathir:29)

Berdasarkan pemahaman di atas, pengukuran IS-USR khususnya sektor perbankan dan secara umum untuk segala macam sektor usaha, sangat diperlukan kaum Muslim di Indonesia sebagai suatu dimensi pengukuran kualitas dan branding kaidah syariah. Pengukuran dengan TSR diyakini merupakan cara pandang umat Muslim menetapkan kontruksi model pengukuran secara matematis terhadap suatu sistem apapun yang dialami umat manusia dalam menjalani kehidupannya di dunia. Harus selalu kaffah, berdimensi dunia akherat, melibatkan unsur $(\theta)$-value dalam setiap variabel yang akan dicapainya. Dengan $(\theta)$-value kita diingatkan banyak peristiwa, kejatuhan kejatuhan Lehman Brothers, kasus Bank Century, para Koruptor yang tetap rakus walaupun sudah kaya raya dan banyak lagi yang lainnya. Satu hal yang harus dimulai, implementasikan ( $\theta$ )-value disetiap fungsi atau obyek pengamatan kita, termasuk dalam Pengukuran Kinerja BPRS.

\section{LANDASAN TEORI}

\section{Identifikasi Kinerja BPRS}

BPRS Muamalat Harkat Bengkulu adalah sebuah Institusi Perbankan, dengan misi dan visi operasionalnya adalah melakukan pengumpulan atau kolektibilitas dana (fund rising) dari masyarakat yang mempuyai surplus dan memberikan pinjaman/pembiayaan kepada masyarakat yang memerlukan. Karenanya BPRS adalah merupakan institusi bisnis bukan lembaga sosial. Operasional bisnis BPRS adalah jasa pelayanan kepada masyarakat, karenanya kepercayaan masyarakat merupakan suatu persyaratan mutlak.

Kajian (Roy A.et.al., 2013) yang terkait dengan identifikasi dimensi pengukuran Islamic Rural/Small Bank atau MFI yang didapatkan dari jurnal dan artikel ilmiah dari seluruh dunia menggambarkan data sebagai berikut:

Tabel 1. Frekuensi Pengukuran Kinerja

\begin{tabular}{lcc}
\hline Measurement dimensions & Frequency (out of 71 studies) & Weight (\%) \\
\hline Financial performance & 37 & 24 \\
Outreach & 28 & 18 \\
Sustainability & 25 & 16 \\
Efficiency & 18 & 12 \\
Others & 16 & 10 \\
Social performance & 16 & 10 \\
Institutional characteristics & 7 & 5 \\
Productivity & 4 & 3 \\
IGovernance & 3 & 2 \\
\hline
\end{tabular}

atau di formulasikan, dieksekusi dan selanjutnya dimonitor, dikontrol lalu dievaluasi.

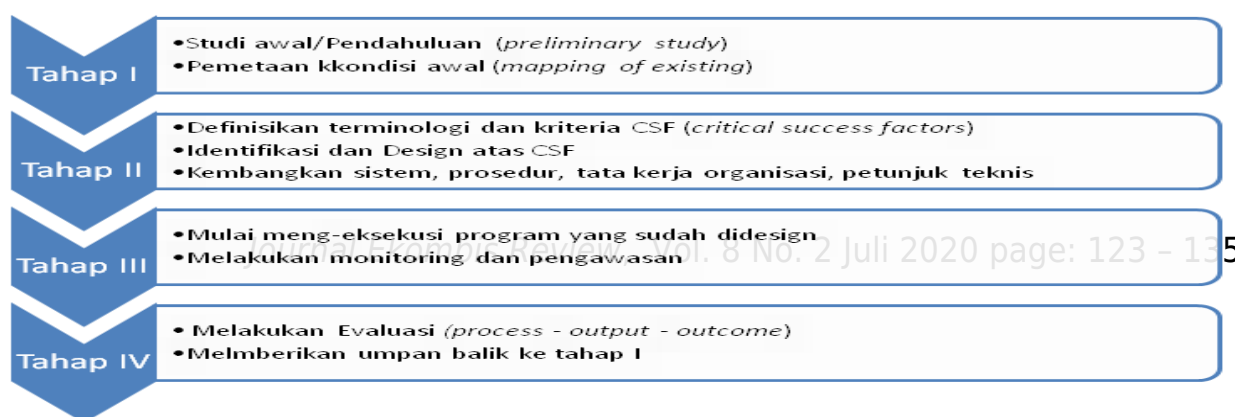




\section{Clients Satisfaction}

Client Satisfaction (CS) adalah identifikasi kepuasan pelanggan. Dalam hal ini pelanggan BPRS adalah para penabung (debitor) atau para peminjam (creditor) atau pengguna jasa BPRS lainnya, misalnya dalam keperluan transaksi lain jasa keuangan lainnya Dalam pengukuran CS dalam BPRS Muammalat Harkat Bengkulu digunakan pembatasan bahwa clients sebagai responnden hanya penabung dan peminjam.

Identifikasi dan pengukuran CS ini bisa berupa pelayanan, dan utamanya adalah tingkat kewajaran dari biaya yang terjadi karena kegiatan menabung dan meminjam. Nilai atau skor tingkat kepuasan nasabah akan diukur berdasarkan hasil quesioner dengan skala linkert 1-5.Pengukuran CS biasanya dilakukan secara periodik, setiapp tahunan dan melibatkan keseluruhan nasabah sebagai bagian dari kegiatan manajemen strategis organisasi.

\section{Employee Engangement}

Dalam pemahaman yang umum Employee Engangement (EE) adalah suatu kondisi yang diilustrasikan sebagai keterlibatan karyawan dalam operasional organisasi atau bisnis pada umumnya. Dalam hal pengukuran EE dinyatakan dalam dua hal yaitu Employee Satisfaction and Commitment (ESC) dan aktualisasi pelaksanaan pendidikan dan pelatihan untuk karyawan.

Pada manajemen organisasi secara umum, pengukuran ESC juga merupakan refleksi beberapa kriteria seperti loyalitas karyawan, turn over karyawan, produktivitas karyawan dan berbagai inovasi atau kreatifitas dalam mendukung kegiatan operasional. Dalam BPRS, ESC menjadi sangat penting karena operasi BPRS adalah jasa keuangan yang memerlukan pelayanan dengan keahlian yang cukup bagus.

\section{Business Countinuity}

Business continuity adalah suatu identifikasi dan ukuran tentang keberlanjutan bisnis yang direpresentasikan dengan beberapa KPI. Karena dimensi pengukuran atas keberlanjutan bisnis ini mencakup objek yang cukup luas, maka pilihan atas KPI sebagai representasi harus dipilih secara seksama. Dalam hal ini Manajemen BPRS Muammalat Harkat telah menetapkan beberapa KPI, diantaranya adalah pengendalian NPF, liquiditas, CAR dan alokasi biaya promosi.

Ukuran atas ke-4 KPI tersebut diatas, dianggap sudah mereflesikan kondisi keberlajutan bisnis yaitu dengan menjadi agar kredit yang disalurkan tetap lancar sesuai rencana, menjaga liquiditas yang cukup agar masih bisa melayani nasabah dengan baik, menjaga kepemilikan kapital atau modal pemilik untuk memenuhi atau peraturan yang berlaku, dan melakukan perencanaan alokasi biaya untuk promosi, inovasi produk maupun melakukan penelitian terkait kegiatan operasional BPRS. Langkah tersebut di atas, merupakan strategi jangka menengah dan jangka panjang yang harus mendapatkan perhatian yang serius untuk menjaga keberlanjutan bisnis.

\section{Community Involvement}

126 | Dharma Setiawan; Katra Pramadeka ; Pengukuran Kinerja BPRS Berdasarkan Perspektif Tauhidy String Relation (TSR) 
Community involvement adalah suatu bentuk kegiatan yang dilakukan oleh organisasi atau institusi tertentu yang melibatkan masyarakat umum disekitar baik sebagai objek maupun subjek atas kegiatan tersebut diatas. Bagi BPRS Muammalat Harkat, kegiatan yang melibatkan masyarakat tersebut diatas diidentifikasi dengan kegiatan atau pelaksanaan atas Corporate Social Responsibility (CSR) atau zakat, kegiatan sosial keagamaan dan kegiatan terkait dengan zakat karyawan.

\section{Pengukuran Skor Pada Key Performance Indicator (KPI)}

Metode atau cara pengukuran skor pada KPI adalah suatu tahapan yang sangat krusial, sensitif dan pemicu perbedaan pendapat yang berkepanjangan bagi beberapa bagian atau divisi dalam organisasi perusahaan. Karenanya harus dibuat secara rinci, detail dan seksama dalam suatu prosedur baku. Dalam perusahaan skala besar, biasanya memiliki "buku Pedoman" atau Guidence Book, yang memuat secara rinci, bagaimana cara menilai skor KPI dan darimana sumber data yang didapatkan.

Pada BPRS Muammalat Harkat dengan kategori merupakan organisasi bisnis dengan skala menengah kecil, maka penetapannya dilakukan dengan cara sederhana mengacu beberapa hal standar yang sudah dipahami secara umum.

\section{Instrument/Alat Ukur Kinerja}

Instrument atau alat ukur kinerja, sudah banyak dikembangan oleh para ahli manajemen. Pada mulanya terminologi "performance measurement" adalah suatu alat ukur yang umum dan biasa digunakan untuk sektor keuangan saja. Tapi seiring dengan perkembangan pemahaman kinerja dalam ilmu manajemen organisasi maka istilah atau terminologi tersebut dikembangkan untuk ukuran seluruh proses dalam organisasi. Metode yang banyak digunakan adalah BSC, MBCfPE, KPKU, McKency Modul, ISO, Deming Prize dan banyak sekali versi modifikasi daripadanya.

BPRS sebagai institusi bisnis juga menetapkan metode pengukuran kinerja, dan kemudian diadopsi dan dimodifikasi sesuai dengan dengan keperluan, termasuk berapa macam variabel terpilihnya dan berapa jumlah Key Performance Indicators (KPI) yang terlibat tiap variabelnya.

\section{Balance Scorecard (BSC)}

Sejak diintroduksi oleh Kaplan dan Norton tahun 1980-an sampai sekarang sudah di klaim mencapai generasi ke-3, bahwa konsep BSC telah berkembang sedemikian rupa dan mendapat respon yang sangat positif di dunia bisnis. Banyak perusahaan yang telah sukses mengimplementasikan konsep BSC di seluruh dunia. Hampir semua perusahaan multinational megenal konsep BSC dengan baik, ada yang mengimplemantasikan secara utuh dan ada yang mengadopsi dan memodifikasinya sesuai dengan keperluan saja.

Pada prinsipnya institusi/organisasi bisnis dengan skala kecil juga direkomendasikan untuk mengimplementasikan konsep BSC dalam upaya untuk pengukuran kinerja. Termasuk institusi selevel BPRS. Komponen utama dalam BSC adalah 1). Financial, 2). Customer, 3) Internal Business, 4). Learning \& Growth. Dan inti keberhasilannya adalah menjaga keseimbangan ke-4 faktor tersebut.

\section{Metode Analisis}

\section{METODE PENELITIAN}

Pendekatan alat analisis atau metode yang digunakan secara kualitatif dan kuantitatif dengan alat ukur berupa Sistem Managemen Kinerja (SMK) atau 
Performance Management System (PMS), yang secara umum sudah banyak diimplementasikan oleh banyak organisasi bisnis beberapa dekade terakhir. Model design SMK mengacu dan mengadopsi pada beberapa prinsip utamanya adalah Balance Scorecard (BSC). Prinsip dan cara penilaiannya dengan mengadopsi model tersebut di atas, kemudian disesuaikan dengan tingkat prioritas atau kepentingan dalam implementasi di institusi yaitu Bank Pembiayaan Rakyat Syariah (BPRS).

Model manajemen pada penganut sistem liberalisme dan kapitalisme yang masih merupakan mainstream pada saat ini, kemudian dirancang dan dikolaborasikan dengan konsep dimensi moralitas, etika dan nilai-nilai sosial dengan pendekatan berdasarkan perspektif dan aqidah Islam, yaitu pendekatan metodologi Tawhidy String Relation (TSR). Hasil paduan SMK dan TSR selanjutnya dikombinasikan untuk memandang masalah sistem manajemen dan penilaian kinerja institusi menjadi suatu satu kesatuan secara kaffah, berdimensi duniawi dan ukhrowi, berwawasan dunia akherat

\section{HASIL DAN PEMBAHASAN}

\section{Pembahasan}

\section{Data Theta $(\boldsymbol{\theta})$}

Pengukuran nilai $(\theta)$ dilakukan reguler setiap tahun dengan menggunakan data primer. Dalam hal ini, yang berlaku sebagai responden adalah stakeholders. Jumlah responden 274 masih berupa sampling, akan tetapi sudah hampir merupakan sebagian besar stakeholders. Hasil dari pengukuran bisa dilihat dalam tabel berikut:

Tabel 1 Hasil Pengukuran Data Theta $(\theta)$

\begin{tabular}{|c|c|c|c|c|c|}
\hline Sample no. & Data $\Theta(\times 1)$ & Data $\Theta(\times 2)$ & Data $\Theta(\times 3)$ & Data $\Theta(\times 4)$ & Data $\Theta(\times 5)$ \\
\hline 1 & 3,67 & 3,83 & 3,33 & 3,67 & 3,50 \\
\hline 2 & 3,83 & 3,50 & 3,17 & 3,50 & 4,00 \\
\hline 3 & 4,00 & 3,33 & 3,50 & 3,50 & 3,67 \\
\hline 4 & 4,00 & 4,00 & 3,50 & 3,50 & 3,67 \\
\hline 5 & 4,00 & 3,67 & 3,50 & 3,50 & 3,80 \\
\hline . &. &. &. &. &. \\
\hline . & . & . & . & . & . \\
\hline. & . &. & . &. & . \\
\hline 270 & 4,17 & 3,67 & 4,50 & 3,50 & 3,83 \\
\hline 271 & 4,50 & 4,00 & 4,50 & 4,00 & 4,00 \\
\hline 272 & 3,50 & 3,33 & 3,17 & 3,00 & 3,00 \\
\hline 273 & 3,00 & 3,67 & 4,67 & 5,00 & 5,00 \\
\hline 274 & 3,00 & 3,00 & 3,00 & 3,00 & 3,00 \\
\hline Avera和月 & naukెㅛㅇㅛ n & $(\theta){ }^{3} \mathrm{~d} / 85$ & menđౌa8ి & skaßa,8zk & $5)^{3,8]}$ \\
\hline
\end{tabular}

nilai tengah adalah 3 , menunjukan bahwa secara umum pengukuran nilai $(\theta)$ mendapatkan hasil yang cukup baik (di atas 3). Sebagaimana digambarkan dalam kajian pustaka, bahwa nilai $(\theta)$ adalah merupakan ukuran moralitas, etika dan nilai nilai sosial dalam variabel tertentu yang dijalankan oleh BPRS Muamalat Harkat, maka secara umum bisa dikatakan bahwa bisnis BPRS Muamalat Harkat dijalankan dengan cukup baik.

Nilai $(\theta)$ tertinggi yaitu $(3,91)$ didapatkan pada variabel $(X 5)$ yaitu community envolvement atau keterlibatan masyarakat dalam mendukung kegiatan operasional BPRS atau sebaliknya. Nilai ukuran moralitas, etika dan nilai nilai sosial yang relatif 
tinggi menjadi suatu ciri yang khas sebuah BPRS dimana suatu bisnis yang dijalankan dan dikelola di daerah pedesaan atau dengan kategori interaksi dalam masyarakat masih cukup kental. Sedangkan nilai $(\theta)$ terendah (3.83) adalah pada variabel (X4) yaitu kontinuitas bisnis. Hal ini menunjukan suatu ukuran yang perlu disadari bersama ukuran moralitas, etika dan nilai nilai sosial relatif kecil untuk suatu ukuran bisnis dengan ukuran kecil, modal terbatas, sumberdaya lainnya juga terbatas. Kontinuitas bisnis perlu perencanaan strategis yang baik, perlu sumberdaya yang cukup.

\section{Data Pengukuran Tingkat Kepuasan}

Data kepuasan (satisfaction index) dilakukan setiap tahun oleh BPRS Muamalat Harkat untuk mengetahui seberapa besar tingkat kepuasan stakeholders terutama para peminjam, para penabung dan karayawan. Data ini menjadi sangat penting dan sangat strategis untuk mengetahui seberapa besar tingkat kepuasan, bahkan ukuran clients satisfaction dan employee satisfaction, telah ditetapkan menjadi variabel tersendiri dalam pengukuran kinerja. Jumlah responden yang mengisi kuesioner tidak sama dimana penabung ada 74 orang, peminjam 109 orang dan karyawan 35 orang. Berikut adalah data mengenai pengukuran tingkat kepuasan:

Tabel 2 Pengukuran Tingkat Kepuasan

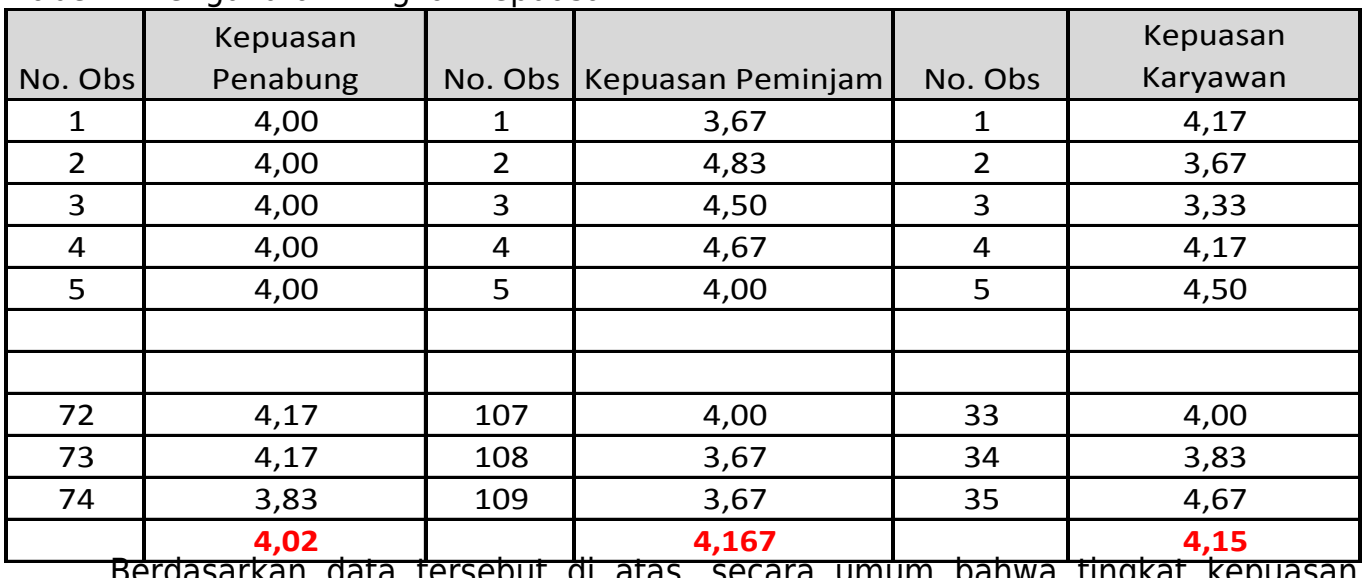
penabung, peminjam dan karyawan sangat bagus (di atas 4). Dengan berbagai macam alasan yang menyertainya dan pengalaman berdasarkan realitas di lapangan, data ini menunjukkan suatu ukuran atas keberadaan bisnis BPRS yang masih dipercaya oleh masyarakat. Nilai di atas 4 atas skala (1-5) adalah kondisi yang sangat baik.

Bila diamati lebih dalam, bahwa nilai terendah dalam ukuran satisfaction adalah penabung $(4,02)$ memberi gambaran akan potensi masalah atau perlu keseriusan yang lebih bagi BPRS Muamalat Harkat untuk mampu melayani para penabung lebih baik lagi. Artinya dilihat dari segi penabung kurang respek dibandingkan dari segi peminjam dan karyawan.

\section{Data Operasional BPRS Muamalat Harkat}

Data Realisasi Kinerja Usaha, merupakan kumpulan dari semua ukuran atas kinerja BPRS Muamalat Harkat selama tahun 2013. Data ini menjadi sangat penting 
untuk memberi informasi kepada share holder dan stakeholders tentang posisi kinerja dan keberadaan/hasil pencapaian perusahaan. Pada dasarnya data ini terdiri dari 3 kriteria utama yaitu:

1. Data hasil pencapaian kinerja, berupa data realisasi operasional dibandingkan dengan data target, kemudian dihitung penilaian skor-nya.

2. Data mengenai ukuran kepuasan (satisfaction Index) atas para penabung, peminjam dan karyawan.

3. Data mengenai ukuran nilai $(\theta)$, yang esensinya adalah ukuran moralitas etika dan nilai nilai sosial dalam pencapaian variabel bisnis.

\section{Statitik dan Analisis Data}

Tabel 3 Pengukuran $\theta$-value, untuk kategori variabel "Profitabilitas (X1)"

\begin{tabular}{|ll|}
\hline \multicolumn{1}{|c|}{ Deskripsi Statistik } & THETA $(\boldsymbol{\theta})-\mathbf{X} \mathbf{1}$ \\
\hline Mean & 3.883698 \\
Median & 4.000000 \\
Maximum & 5.000000 \\
Minimum & 2.000000 \\
Std. Dev. & 0.414386 \\
Skewness & -0.588640 \\
Kurtosis & 4.785646 \\
Jarque-Bera & 52.22577 \\
Probability & 0.000000 \\
Sum & 1064.133 \\
Sum Sq. Dev. & 46.87830 \\
Observations & 274 \\
\hline
\end{tabular}

Sumber: Olah Data, 2020

Pada pengukuran data statistik individu menunjukan nilai $\theta$-value untuk variabel profitabilitas (X1) sebesar 3,88 dari skala Likert (5) yang berarti diatas nilai tengah (3), yang berarti bahwa penilaian stakeholders BPRS Muammalat Harkat Bengkulu atas variabel profitabilitas sebagaimana didapatkan dari rencana target usaha dari segi perencanaan, pelaksanaan dan evaluasi bisa diterima dengan baik. Sedangkan statistik dengan tingkat probability yang cukup rendah, data yang diambil sudah cukup bagus untuk memenuhi kriteria distribusi normal.

Tabel 4 Pengukuran $\theta$-value, untuk kategori variabel "Clients Satisfaction (X2)" dan seterusnya

\begin{tabular}{|lccccc|}
\hline & THETA X1 & THETA X2 & THETA X3 & THETA X4 & THETA_ X5 \\
Mean & 3.883698 & 3.864355 & 3.859489 & 3.834307 & 3.907056 \\
Median & 4.000000 & 4.000000 & 4.000000 & 4.000000 & 4.000000 \\
Maximum & 5.000000 & 5.000000 & 5.000000 & 5.000000 & 5.000000 \\
Minimum & 2.000000 & 1.833333 & 2.500000 & 1.833333 & 1.000000 \\
Std. Dev. & 0.414386 & 0.409680 & 0.427038 & 0.444401 & 0.467441 \\
Skewness & -0.588640 & -0.765426 & -0.398767 & -0.855561 & -1.998931 \\
Kurtosis & 4.785646 & 5.743512 & 3.924975 & 5.909980 & 13.17673 \\
Jarque-Bera & 52.22577 & 112.6867 & 17.02953 & 130.1034 & 1364.847 \\
Probability & 0.000000 & 0.000000 & 0.000200 & 0.000000 & 0.000000 \\
\hline
\end{tabular}

130 | Dharma Setiawan; Katra Pramadeka ; Pengukuran Kinerja BPRS Berdasarkan Perspektif Tauhidy String Relation (TSR) 


\begin{tabular}{|lrrrrr|}
\hline Sum & 1064.133 & 1058.833 & 1057.500 & 1050.600 & 1070.533 \\
Sum Sq. Dev. & 46.87830 & 45.81965 & 49.78477 & 53.91530 & 59.65080 \\
Observations & 274 & 274 & 274 & 274 & 274 \\
\hline
\end{tabular}

Sumber : Olah Data, 2020

Pada pengukuran data statistik individu menunjukan nilai $\theta$-value untuk semua variabel $(X 1, X 2, X 3, X 4$ dan $X 5)$ didapatkan hasil sebagaimana tabel diatas dari skala Likert (5) yang berarti diatas nilai tengah (3), yang berarti bahwa penilaian stakeholders BPRS Muammalat Harkat Bengkulu atas semua variabel sebagaimana didapatkan dari rencana target usaha dari segi perencanaan, pelaksanaan dan evaluasi bisa diterima dengan baik.

\section{Pungukuran Clients Satisfaction}

Tabel 5 Kepuasan Penabung

\section{Deskripsi Statistik}

Mean

Median

Maximum

Minimum

Std. Dev.

Skewness

Kurtosis

Jarque-Bera

Probability

Sum

Sum Sq. Dev. Observations

\section{Kepuasan Penabung}

4.022523

4.000000

5.000000

3.000000

0.320915

$-0.077097$

5.988530

27.61151

0.000001

297.6667

7.518018

74

Sumber : Olah Data, 2020

Data hasil tingkat kepuasan penabung merupakan informasi atas berbagai persoalan terkait dengan perspektif atau akseptabilitas para penabung. Hasil 4.02 (5) menunjukan ukuran tingkat kepuasan yang cukup bagus.

Tabel 6 Kepuasan Peminjam

\begin{tabular}{|lc|}
\hline Deskripsi Statistik & Kepuasan Peminjam \\
\hline Mean & 4.166667 \\
Median & 4.000000 \\
Maximum & 5.000000 \\
Minimum & 3.000000 \\
Std. Dev. & 0.405720 \\
Skewness & -0.061903 \\
Kurtosis & 2.929375 \\
Jarque-Bera & 0.092269 \\
Probability & 0.954914 \\
Sum & 454.1667 \\
Sum Sq. Dev. & 17.77778 \\
Observations & 109 \\
\hline
\end{tabular}

Sumber : Olah Data, 2020 
Sedangkan data hasil tingkat kepuasan peminjam merupakan informasi atas berbagai persoalan terkait dengan perspektif atau akseptabilitas para peminjam. Hasil 4.17 (5) menunjukan ukuran tingkat kepuasan yang cukup bagus.

Tabel 7 Pengukuran Employees Satisfaction \& Commitment

\begin{tabular}{|lc|}
\hline Deskripsi Statistik & Kepuasan Karyawan \\
\hline Mean & 4.147619 \\
Median & 4.166667 \\
Maximum & 5.000000 \\
Minimum & 3.333333 \\
Std. Dev. & 0.395587 \\
Skewness & -0.143444 \\
Kurtosis & 2.464685 \\
Jarque-Bera & 0.537932 \\
Probability & 0.764169 \\
Sum & 145.1667 \\
Sum Sq. Dev. & 5.320635 \\
Observations & 35 \\
\hline
\end{tabular}

Sumber : Olah Data, 2020

Pada tingkat employees satisfaction \& commitment adalah pengukuran tingkat kepuasan dan loyalitas karyawan. Ukuran yang digunakan adalah sebagaimana terlihat dalam daftar pertanyaan yang tercermin dalam kuesioner. Hasil yang didapatkan sebesar 4.15 (5) adalah ukuran yang bagus sekali.

\section{KESIMPULAN DAN SARAN}

\section{Kesimpulan}

Dari hasil analisa dan pembahasan tentang Kinerja BPRS Muamalat Harkat berdasarkan metodologi Tawhidy String Relation maka dapat disampaikan beberapa identifikasi dan analisis sebagai berikut: Hasil keseluruhan pengukuran nilai/skor atas variabel tingkat profitabilitas adalah (35\%)(100)(3.88). Participatory cukup tinggi, $35 \%$, dan hasil pencapaian kinerja rasional mencapai nilai tertinggi 100 . Hasil pengukuran nilai $(\theta)$ dengan menggunakan skala Likert (1-5), dengan nilai tengah adalah 3, menunjukkan bahwa secara umum pengukuran nilai $(\theta)$ mendapatkan hasil yang cukup baik (di atas 3). Hasil pengukuran variabel (15\%)(87.7)(3.86). Secara umum tingkat kepuasan penabung, peminjam dan karyawan sangat bagus dimana nilai di atas 4. Hal ini menunjukkan bahwa keberadaan bisnis BPRS Muamalat Harkat masih dipercaya oleh masyarakat. Hasil pengukuran variabel karyawan adalah (20\%)(100)(3.86). Pengukuran data statistik individu menunjukkan nilai 0value untuk variable profitabilitas $(X 1)$ sebesar 3,88 , yang berarti bahwa penilaian stakeholders BPRS Muamalat Harkat Bengkulu atas variable profitabilitas yang didapatkan dari rencana target usaha dari segi perencanaan, pelaksanaan dan evaluasi bisa diterima dengan baik. Hasil pengukuran variabel keberlanjutan usaha adalah (20\%)(50)(3.83). Pengukuran data statistik individu menunjukkan nilai 0-value untuk variable client satisfaction (X2) sebesar 4,02 (5), yang berarti bahwa tingkat 
kepuasan para penabung cukup bagus. Sementara tingkat kepuasan peminjam nilainya sebesar 4.17 (5), yang berarti tingkat kepuasan yang cukup bagus. Hasil pengukuran variabel aspek komunitas adalah (10\%)(89.9)(3.91). Tingkat kepuasan dan loyalitas karyawan nilainya sebesar 4.15 (5) yang berarti bagus.

Secara umum hasil pengukuran nilai $(\theta)$ sangat baik, mendekati nilai 4 dengan skala Likert(5). Nilai terbesar pada variabel aspek komunitas 3,91 dan terendah pada aspek keberlanjutan bisnis 3,83. Penjelasan yang umum BPRS memang harus dekat dengan komunitas atau warga setempat. Dan kondisi terlemah adalah tentang keberlanjutan bisnis, sebagaimana bisnis ukuran kecil pada umumnya. Nilai $(\theta)$ terkecil juga ditunjukan pada nilai pencapaian rasional yang paling kecil yaitu hanya mencapai 50. Pertumbuhan keuntungan sangat tinggi, mencapai 39\%, sedangkan NPF juga sangat tinggi, hal ini mengindikasikan suatu kebijakan yang kurang cocok. Seolah shareholders menginginkan laba yang tinggi, dengan tidak mencadangkan kerugian atas NPF yang juga tinggi. Akibatnya secara logis keberlanjutan usaha menjadi dipertaruhkan.

\section{Saran}

Dalam penelitian ini peneliti dapat memberikan saran-saran sebagai berikut: Penelitian ini dapat dijadikan bahan referensi dalam menilai Kinerja Bank khususnya Bank Pembiayaan Rakyat Syariah (BPRS) dan umumnya Bank Umum Syariah (BUS). Penelitian ini dapat dijadikan bahan referensi bagi Otoritas Jasa Keuangan (OJK) dalam menilai tingkat kesehatan Bank. Untuk manajemen BPRS Muamalat Harkat kinerja yang sekarang perlu ditingkatkan lagi terutama dalam factor pembiayaan yang bermasalah. Agar pembiayaan yang bermasalah tersebut segera di atasi sehingga nantinya akan meningkatkan profitabilitas dan kepercayaan nasabah yang menabung di bank.

\section{DAFTAR PUSTAKA}

Adiwarman A Karim, 2011. Bank Islam Analis Fiqh dan Keuangan Jakarta: PT. Raja Grafindo Persada

H. Syakir Sula, 2012. Sistem Perbankan Syariah di Indonesia, Yogyakarta: Fajar Media Press.

Kasmir, 2008. Manajemen Perbankan, Jakarta: PT. Raja Grafindo Persada.

Masudul Alam Choudhury, Handbook of Tauhidy String Relation.

Panji Adam, 2018. Fatwa-fatwa Ekonomi Syariah, Jakarta: Amzah

Statistik Perbankan Syariah Indonesia tahun 2012, 2013 yang diterbitkan oleh OJK.

Undang-undang No. 10 tahun 1998 Tentang Perbankan.

Undang-undang No. 21 tahun 2008 Tentang Perbankan Syariah.

Wibowo, 2011, Manajemen Kinerja, Jakarta: PT. RajaGrafindo Persada 